\title{
SCREENING OF ABSORBING GRAINS IN PLASMA WITH A FLOW
}

\author{
YU.O. TYSHETSKIY, S.V. VLADIMIROV
}

PACS 52.27.Lw, 52.40.Kh (C) 2011
School of Physics, University of Sydney

(Sydney, NSW 2006, Australia; e-mail: y. tyshetskiy@ physics. usyd.edu. au)
The electrostatic shielding of a charged absorbing object (dust grain) in a flowing collisionless plasma is investigated by using the linearized kinetic equation for plasma ions with a point-sink term accounting for the ion absorption on the object. The effect of absorption on the attractive part of the dust grain potential distribution in plasma is investigated. For subthermal ion flows, the attractive part of the grain potential in the direction perpendicular to the ion flow can be significantly reduced or completely destroyed, depending on the absorption rate (proportional to the surface area of a grain). For superthermal ion flows, however, the effect of absorption on the grain attraction in the direction perpendicular to the ion flow is shown to be exponentially weak. It is thus argued that, in the limit of superthermal ion flow, the effect of absorption on the grain potential distribution in plasma can be safely ignored for typical grain sizes relevant to complex plasmas.

The problem of screening of a test (non-absorbing) charged particle in unmagnetized anisotropic plasmas is known since the late $1960 \mathrm{~s}$, starting with the works of Montgomery et al. [1] and Cooper [2]. Cooper's solution of the screening problem, obtained for weakly anisotropic collisionless plasmas, implies that two likecharged test particles aligned perpendicularly to the anisotropy axis will attract each other electrostatically, if they are at a large enough distance from each other. This attraction can play a vital role in the formation of dust crystals in complex plasmas [3]. However, the absorption of ions by a particle affects the screening and might change, or even eliminate completely, the attractive part of the screening potential.

In this work, we investigate how the absorption of plasma ions by a dust particle (probe) affects the screening and, in particular, how it affects the possibility of the attraction between like-charged absorbing particles in anisotropic plasmas. We consider a small spherical absorbing body (grain) of charge $Q_{d}$, either moving in isotropic homogeneous collisionless plasma with velocity $\mathbf{u}$, or immersed in a homogeneous collisionless plasma with a uniform flow $\mathbf{u}$. The stationary kinetic equation for ions in the reference frame of the grain is

$\mathbf{v} \cdot \frac{\partial f}{\partial \mathbf{r}}-\frac{e}{m_{i}} \nabla \phi(\mathbf{r}) \cdot \frac{\partial f}{\partial \mathbf{v}}=-\delta(\mathbf{r}) v \sigma(v) f$

where $f=f(\mathbf{r}, \mathbf{v})$ is the ion distribution function, $\phi(\mathbf{r})$ is the self-consistent potential of the grain in plasma. The right-hand side (rhs) of (1) represents the pointsink approximation of ion collection by the grain [4$7]$, in which $\delta(\mathbf{r})$ is the Dirac delta-function, and $\sigma(v)$ is the ion collection cross-section of the body, which we assume to be isotropic, $\sigma(\mathbf{v})=\sigma(v)$ [the criterion of validity of this approximation can be expressed as $\sqrt{\sigma} / \lambda_{a}<1$, where $\lambda_{a}$ is the characteristic length scale, at which the anisotropy in the shielding of the grain by plasma becomes significant]. In collisionless plasma, $\sigma(v)$ is given by the Orbital Motion Limited (OML) theory [3], $\sigma(v)=\sigma_{\mathrm{OML}}(v)=\pi a^{2}\left(1-2 e \phi_{s} / m_{i} v^{2}\right)$, where $\phi_{s}$ is the surface potential of the grain, and $a$ is the grain radius.

Plasma electrons are assumed to be Boltzmanndistributed, $n_{e}=n_{0} \exp \left(e \phi / T_{e}\right)$, where $n_{0}$ is the unperturbed plasma density, and $T_{e}$ is the electron temperature in energy units. The electron flux absorbed by the grain is assumed to compensate the absorbed ion flux, so that the grain charge $Q_{d}$ remains constant. The set is coupled by the Poisson's equation: $-\nabla^{2} \phi=4 \pi e\left(n_{i}-n_{e}\right)+4 \pi Q_{d} \delta(\mathbf{r})$, where $n_{i}=\int f d \mathbf{v}$ is the ion number density, and $Q_{d} \delta(\mathbf{r})$ approximates the charge density of the grain, which is located at $\mathbf{r}=\mathbf{0}$. This delta-function approximation is justified for grains small compared to the length scale of plasma screening.

In the absence of the grain, the plasma is assumed homogeneous and quasineutral, with no electric field $\left(\phi_{0}=0\right)$, and the ion distribution function $f_{0}(\mathbf{v})$. The grain perturbs the plasma, inducing an electric field $-\nabla \phi_{p}(\mathbf{r})$ in the plasma and perturbing the distribution functions of ions, $f(\mathbf{r}, \mathbf{v})=f_{0}(\mathbf{v})+f_{p}(\mathbf{r}, \mathbf{v})$. Assuming this perturbation to be small, $\left|f_{p}\right| \ll f_{0}$, we solve the linearized equations and obtain the self-consistent potential 

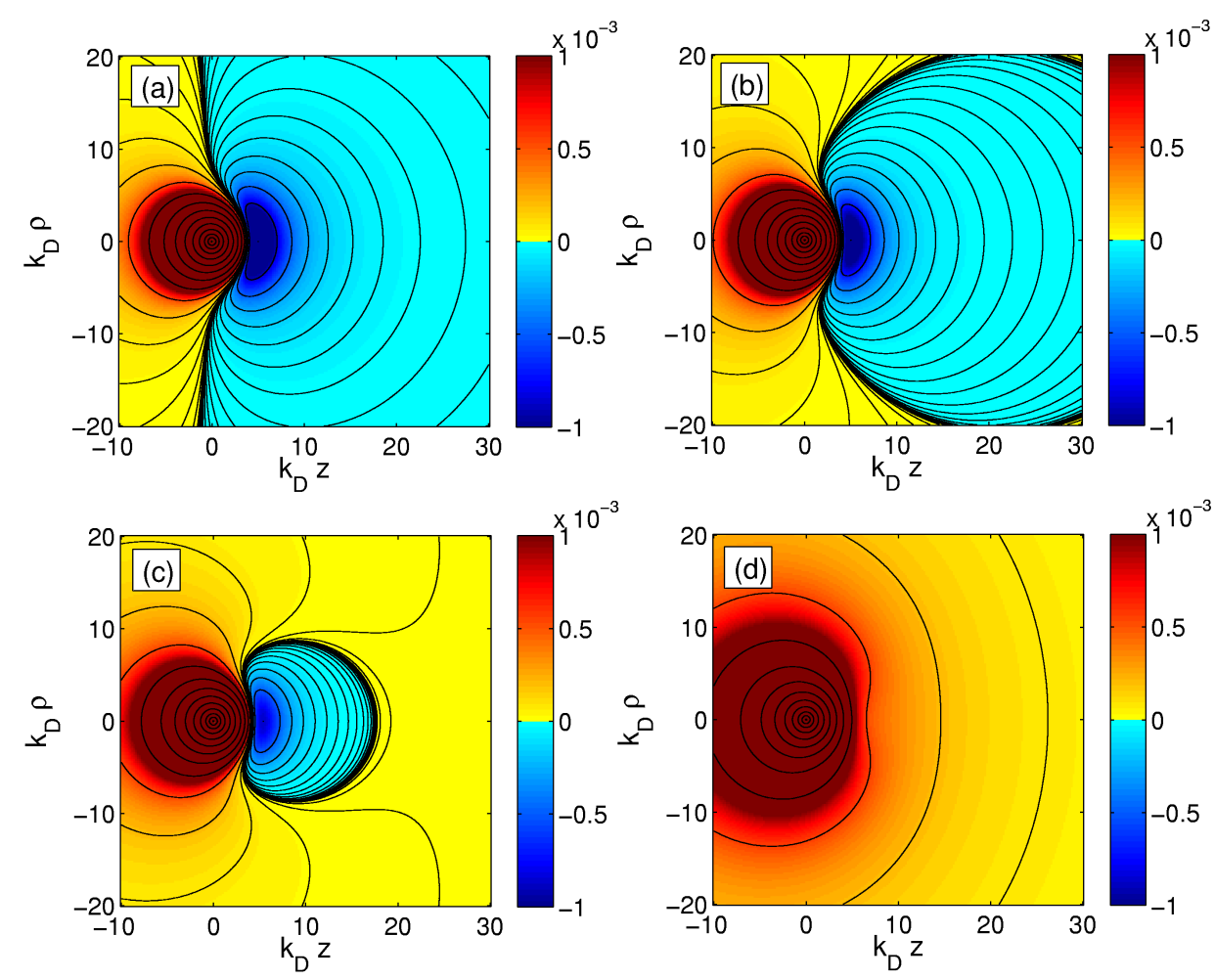

Fig. 1. Total grain potential $\phi_{Q_{d}}+\phi_{\text {abs }}$ (normalized to $Q_{d} / \lambda_{D}$ ), in case of subthermal flow, for different grain sizes: panel $(a): k_{D} a=0$ (no absorption), panel $(b): k_{D} a=10^{-2}$, panel $(c): k_{D} a=2.5 \cdot 10^{-2}$, panel $(d): k_{D} a=10^{-1}$. The grain is located at $\rho=z=0$, the ion flow $\mathbf{u}$ is directed from left to right. The $\phi=0$ contour is shown with a thick black solid line on panels $(a)-(c)$ [on panel $(d)$, the potential does not change sign anywhere]. All potentials are plotted for $u / v_{T i}=0.2, \tau=50, z=3, n_{0}=10^{8} \mathrm{~cm}^{-3}$

of the grain in plasma in the form:

$\phi_{p}(\mathbf{r})=\frac{Q_{d}}{2 \pi^{2}} \int \frac{\exp (i \mathbf{k} \cdot \mathbf{r})}{k^{2} D(\mathbf{k})} d \mathbf{k}+$

$+\frac{i e}{2 \pi^{2}} \int \frac{\exp (i \mathbf{k} \cdot \mathbf{r})}{k^{2} D(\mathbf{k})} \delta n_{\mathrm{abs}}(\mathbf{k}) d \mathbf{k} \equiv \phi_{Q_{d}}(\mathbf{r})+\phi_{\mathrm{abs}}(\mathbf{r})$

where $\phi_{Q_{d}}(\mathbf{r})$ is the potential of the test (non-absorbing) charge $Q_{d}$, and $\phi_{\text {abs }}(\mathbf{r})$ is the additional term due to the absorption of ions on the grain, in which $\delta n_{\text {abs }}(\mathbf{k})=$ $\int v \sigma(v) f_{0}(\mathbf{v}) /(\mathbf{k} \cdot \mathbf{v}-i 0) d \mathbf{v}$. The dielectric function $D(\mathbf{k})$ in (2) is given by

$D(\mathbf{k})=1+\frac{k_{D e}^{2}}{k^{2}}-\frac{\omega_{p i}^{2}}{n_{0} k^{2}} \int \frac{\mathbf{k} \cdot \partial f_{0}(\mathbf{v}) / \partial \mathbf{v}}{\mathbf{k} \cdot \mathbf{v}-i 0} d \mathbf{v}$

where $\omega_{p i}=\sqrt{4 \pi e^{2} n_{0} / m_{i}}$ is the ion plasma frequency, and $k_{D e}=\lambda_{D e}^{-1}$ is the inverse electron Debye length, $\lambda_{D e}=v_{T e} / \omega_{p e}$. Approximating $f_{0}(\mathbf{v})$ with a shifted Maxwellian in the reference frame of the grain, the dielectric function $D(\mathbf{k})$ becomes:

$D(\mathbf{k})=$

$$
=1+\frac{k_{D e}^{2}}{k^{2}}+\frac{k_{D i}^{2}}{k^{2}}\left[1+i \sqrt{\frac{\pi}{2}}\left(\frac{\mathbf{k} \cdot \mathbf{u}}{k v_{T i}}\right) W\left(\frac{\mathbf{k} \cdot \mathbf{u}}{\sqrt{2} k v_{T i}}\right)\right],
$$

where $v_{T i}$ is the thermal velocity of plasma ions, and $W(\zeta)=\exp \left(-\zeta^{2}\right) \operatorname{erfc}(-i \zeta)$ is the plasma dispersion function of a real argument.

Below, we consider solutions for $\phi_{p}(\mathbf{r})$ of Eq. (2) in the limits of subthermal $\left(u / v_{T i} \ll 1\right)$ and superthermal $\left(u / v_{T i} \gg 1\right)$ ion flows.

\section{A. Subthermal ion flows, $u \ll v_{T i}$}

This limit is relevant to a situation where a grain is suspended in a weakly anisotropic collisionless plasma with a subthermal flow (e.g., a grain in collisionless presheath), or to a grain slowly moving in an isotropic collisionless plasma. The spatial structure of the corresponding total grain potential $\phi=\phi_{Q_{d}}+\phi_{\text {abs }}$ in this limit, for different grain sizes (i.e., different ion absorption cross-sections), is shown in Fig. 1.

At small distances from the grain $\left(k_{D} r \ll 1\right)$, the potential near the grain is dominated by the isotropic Debye potential, and the role of absorption on the near- 

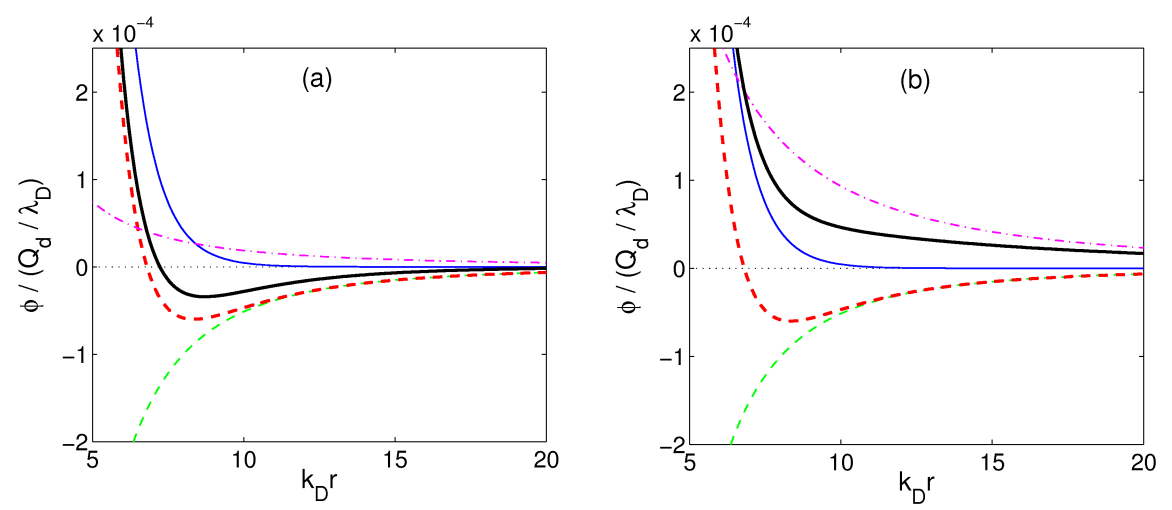

Fig. 2. Potential (normalized to $Q_{d} / \lambda_{D}$ ) in the direction perpendicular to the ion flow, in case of subthermal flow. The thick dashed line shows the potential of a non-absorbing (test) charge, consisting of the Debye and $r^{-3}$ components shown with the thin solid and dashed lines, respectively. The thin dash-dotted line shows the $r^{-2}$ term due to the absorption of ions by the grain, and the thick solid line shows the total potential $\phi_{Q_{d}}+\phi_{\text {abs }}$ of the absorbing charged grain. The potentials are plotted for $u / v_{T i}=0.3, a / \lambda_{D}=2 \times 10^{-3}$ (panel $a$ ), and $a / \lambda_{D}=10^{-2}($ panel $b)$
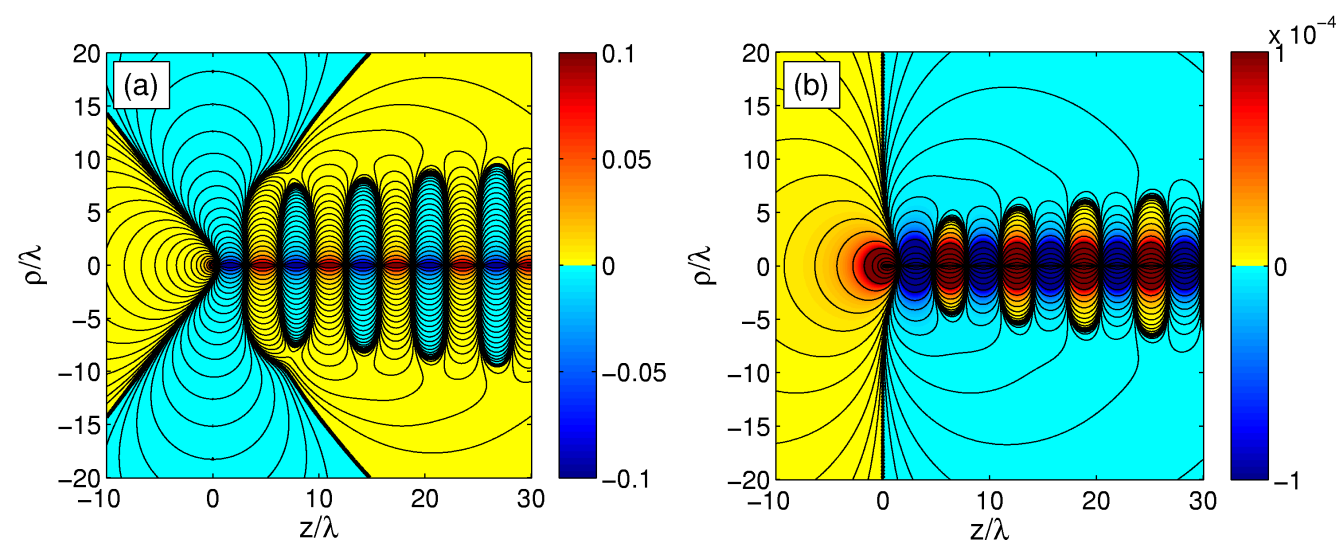

Fig. 3. Plots of $\phi_{Q_{d}}(\rho, z)$ and $\phi_{\text {abs }}(\rho, z)$ (normalized by $\left.Q_{d} / a\right)$ for superthermal ion flows. The grain is located at $\rho=z=0$, the flow velocity $\mathbf{u}$ is directed from left to right. The contours represent the equipotential surfaces (note that here the potential between the contours does not change linearly). The thick contour shows the zero potential surface

grain potential is minor. At large distances from the grain $\left(k_{D} r \gg 1\right)$, the absorption-induced potential $\phi_{\mathrm{abs}}$ dominates, i.e., the far field of the grain in plasma is defined by the absorption of plasma ions on the grain. [This result, obtained here for collisionless plasmas, qualitatively agrees with the findings of Chaudhuri et al. [8] for the dominant role of absorption in the far-field of grains immersed in strongly collisional drifting plasmas.] As seen from Figs. 1 and 2, the absorption of ions by the grain in case of subthermal ion flows changes the structure of the grain potential in a qualitative way: for small grains, it reduces, and for larger grains, it destroys completely the attractive part of the grain potential. One should thus account for the effect of ion absorption on the grain in plasmas with a subthermal ion flow, if one is interested in the effects associated with the asymptotic behavior of the grain potential in the direction perpendicular to the flow, e.g., the interaction of grains and phase transitions in dust crystals and clusters in the plane orthogonal to the ion flow.

\section{B. Superthermal ion flows, $v_{T i} \ll u<v_{s}$}

The limit $v_{T i} \ll u<v_{s}$ (where $v_{s}=\left(T_{e} / m_{i}\right)^{1 / 2}$ is the ion sound velocity) can be relevant, e.g., to dust grains suspended against gravity in a collisionless sheath region of the discharge, or to satellites in the upper ionosphere. In this limit, we can approximate $f_{0}(\mathbf{v})=$ $\lim _{v_{T i} \rightarrow 0} n_{0} \Phi_{M}(\mathbf{v}-\mathbf{u})=n_{0} \delta(\mathbf{v}-\mathbf{u})$. Neglecting the electron response (i.e., assuming that electrons are much hotter than ions, so that electrons do not contribute significantly to the screening [9]), we obtain $D(\mathbf{k})$ and 
$\delta n_{\mathrm{abs}}(\mathbf{k})$ in this limit:

$D(\mathbf{k})=1-1 /\left(k_{\|}-i 0\right)^{2} \lambda^{2}$,

$\delta n_{\mathrm{abs}}(\mathbf{k})=\left(n_{0} / k_{\|}\right) \sigma_{\mathrm{OML}}(u)$

where $k_{\|}$is the wavenumber along the direction of $\mathbf{u}$, and $\lambda=u / \omega_{p i}=\left(u / v_{T i}\right) \lambda_{D i}$. Substituting $D(\mathbf{k})$ and $\delta n_{\text {abs }}(\mathbf{k})$ into (2), we obtain the expressions for $\phi_{Q_{d}}$ and $\phi_{\text {abs }}$ in case of superthermal flow (not shown here), whose plots are shown in Fig. 3.

As seen from Fig. 3, the ion absorption on the grain for superthermal ion flows leads to a qualitative change in the far-field structure of the grain potential $\phi=$ $\phi_{Q_{d}}+\phi_{\text {abs }}$ : instead of the quadrupole-like potential, it becomes the dipole-like potential. However, for typical grain sizes [10], the characteristic distance at which this change occurs is large compared to the characteristic spatial scale of the grain field. Therefore, in case of superthermal flows, the effect of absorption can be safely ignored for typical grain sizes of complex plasmas [10].

1. D. Montgomery, G. Joyce, and R. Sugihara, Plasma Phys. 10, 681 (1968)

2. G. Cooper, Phys. Fluids 12, 2707 (1969).

3. V.E. Fortov et al., Physics-Uspekhi 47, 447 (2004).

4. A.G. Zagorodny, A.V. Filippov et al., Prob. Atomic Sci. Technol.: Plasma Phys. Ser. 12, 99 (2006).

5. A.V. Filippov, A.G. Zagorodny et al., J. Exp. Theor. Phys. 104, 147 (2007).

6. A.V. Filippov, A.G. Zagorodny et al., J. Exp. Theor. Phys. 108, 497 (2009).
7. S.A. Khrapak, B.A. Klumov, and G.E. Morfill, Phys. Rev. Lett. 100, 225003 (2008).

8. M. Chaudhuri, S.A. Khrapak, and G.E. Morfill, Phys. Plasmas 14, 022102 (2007).

9. R. Kompaneets et al., New J. Phys. 10, 063018 (2008).

10. J.D. Huba, NRL Plasma Formulary (Office of Naval Research, Washington, 2007).

Received 19.01.11

\section{ЕКРАНУВАННЯ ПОГЛИНАЮЧИХ ЧАСТИНОК} У ПЛАЗМІ 3 ПОТОКОМ

Ю.О. Тищещъкий, С.В. Владимиров

$\mathrm{P}$ е $з$ ю м е

Електростатичне екранування зарядженого поглинаючого об'єкта (пилової частинки) у беззіткненій плазмі з потоком досліджено на основі лінеаризованого кінетичного рівняння для іонів плазми з врахуванням їх поглинання точковим об'єктом. Досліджено вплив поглинання іонів на притягувальну частину розподілу потенціалу пилової частинки в плазмі. Для дотеплових іонних потоків притягувальна частина потенціалу частинки в напрямі перпендикулярному потоку іонів може бути суттєво послаблена або повністю зникнути, залежно від швидкості поглинання (пропорційної площі поверхні частинки). Для надтеплових іонних потоків показано, що вплив поглинання на притягувальну частину потенціалу частинки в напрямку перпендикулярному потоку іонів експоненціально малий. Зроблено висновок про те, що у випадку надтеплового потоку іонів плазми відносно частинки впливом поглинання на розподіл потенціалу частинки у плазмі можна знехтувати для розмірів частинок, що характерні для комплексних плазм. 